\title{
Probiotics and Natural Defense Function of the Host
}

\author{
Yoichi FUKUSHIMA *\# \\ Manufacturing Services Dept., Nestlé Japan Ltd., NYK Tennoz Building, 2-2-20, Higashi-Shinagawa, Shinagawa-ku, Tokyo \\ 140-0002, Japan \\ \#Present address: Nestlé Research Center, CH-1000 Lausanne 26, Switzerland
}

Received for publication, November 2, 2006

The natural defense systems of animals, including humans, have been developed to maintain the hosts' health by fighting exogenous microbes. Immune systems, which have functions to recognize and keep out exogenous organisms, play a central role in the host defense systems. Intestinal microflora, mainly composed of commensal bacteria, also provide defense functions called colonization resistance to keep out exogenous bacteria. We have been investigating probiotic strains Lactobacillus johnsonii La1 (NCC533) and Bifidobacterium animalis subspp. lactis Bb-12 to elucidate the efficacy of these probiotic strains in strengthening the natural defense system of the host and their potential for risk

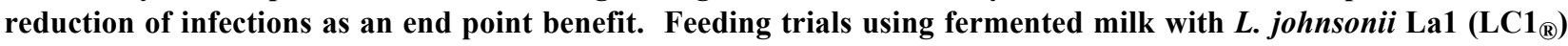
showed that intestinal microflora were improved and blood phagocytic activity, a biomarker for natural immunity, increased in healthy adults. In a feeding trial of LC1 in the elderly, we found that the frequency of infection was reduced by administration of the probiotics. In the LC1-fed elderly, blood phagocytic activity increased, and serum TNF- $\alpha$, an inflammation biomarker, was lowered. Serum albumin, a biomarker for nutritional status, also increased in the LC1-fed elderly, suggesting that probiotic feeding may contribute to regulation of infection through immune system modulation, activation of immunity and suppression of inflammation, and nutritional status improvement. The La1 strain was shown to stimulate the parasympathetic nerve system in vivo, implying that anabolic action might contribute to nutritional status improvement. An anti-inflammatory effect of the La1 strain was also observed in the animal studies using colitis, Helicobacter pylori-infection, and atopic dermatitis models, and a human study in pollen allergy patients. Feeding of the Bb-12 strain in weaning children improved intestinal microflora and increased intestinal IgA production. Probiotics such as L. johnsonii La1 and Bifidobacterium Bb-12 could play a significant role in improving the QOL of human beings through strengthening the natural defense systems of the host. In this paper, we review and discuss our recent work with references to other research.

Key words: probiotics; infection; immunity; nutritional status; human study

\section{INTRODUCTION}

Immune functions play a central role in the natural defense systems, which have developed to maintain the health of the host by fighting exogenous microbes. Intestinal epithelium, interfacing to the external world, has roles of digesting foods and absorbing nutrients over a huge surface area with a thin cellular layer and possesses suitable moistness and temperature for the growth of microbes. The structure and circumstances of the epithelium create an easy target for infection. Therefore, the immune systems are well developed locally in the intestines, and collaborate with the systemic immunity.

Intestinal microflora are composed of approximately one hundred trillion microbes with more than 100 species functioning to protect our body as well as supporting the immune systems. Healthy microflora composed of commensal bacteria exert "colonization resistance,"

*Corresponding author. Mailing address: Nestlé Research Center, CH-1000 Lausanne 26, Switzerland. Phone:+41-21-785-8100. Fax: +41-21-785-8544. E-mail: yoichi.fukushima@rdls.nestle.com which helps to keep out non-residential bacteria including pathogenic ones from the external world $(9,61)$. In germfree animals, production of $\operatorname{IgA}$ is low and immune tolerance is not normally induced, suggesting that intestinal bacteria are also important for the development of normal immune responses (37). Thus, improvement of intestinal microflora could help to strengthen the host defense.

Probiotics are defined as live microorganisms which when administered in adequate amounts confer a health benefit on the host $(11,19)$. There has been increasing evidence showing probiotics reduce the risk of diseases including diarrhea, gastritis, inflammatory bowel diseases and allergy (11). An important health benefit of probiotics could be to strengthen the natural defense systems of the host. Infants are at an age when the immune system is developing (51), and are prone to suffer from infectious diarrhea, whose risk is reduced by the feeding of probiotics $(49,56)$. Recently, some researchers have shown that probiotic strains reduced respiratory infections in children, adults or free-living 
elderly $(8,24,59)$. Scientific evidence gained through human studies is increasing for some probiotic strains, however, there is still insufficient knowledge to explain how the probiotic strains elicit an anti-infectious effect.

Lactobacillus johnsonii La1 (Nestlé culture collection NCC533) is a well documented probiotic strain and its DNA sequences have been fully demonstrated (47). The strain has been shown to strongly adhere to human epithelial cells $(1,3)$, produce bactericidal substances $(2)$, reinforce innate and acquired immunity $(34,52)$ and exert an anti-Helicobacter pylori effect $(12,46)$. Bifidobacterium animalis subspp. lactis $\mathrm{Bb}-12$ is also a well documented probiotic strain used in human studies because of its preventive effect on rotavirus infection and therapeutic use for allergy in children (28). Aiming to evaluate probiotics effect on the natural defense systems of the host, especially on immunity and intestinal microflora, we have been performing clinical and animal studies using these two probiotic strains and have been trying to elucidate their potential on reduction of infection risk and their underlying action mechanisms. In this paper, we review and discuss our recent work with references to other research.

\section{PROBIOTICS AND NATURAL DEFENSE}

Intestinal microflora largely affect immune systems originally developed to resist invasion by exogenous microbes. Probiotic strains fed at several billion per day stimulate the immune systems directly or indirectly through intestinal microflora.

We conducted feeding trials using fermented milk with L. johnsonii La1 ( $\mathrm{LC} 1_{\circledast}$ yogurt) in healthy young females, middle aged adults and pregnant women, and measured blood phagocytic activity using a PHAGOTEST $_{\circledast}$ kit. The phagocytic activity of peripheral phagocytic cells including neutrophils and monocytes is a good biomarker for identifying the status of natural immunity, a major primary response against invading organisms (5). Administration of LC1 fermented milk for 3 weeks significantly increased blood phagocytic activity in healthy adults (Fig. 1). We analyzed fecal samples and found an increase in fecal bifidobacteria and a decrease in Clostridium perfringens, and a viable La1 strain was found in fecal specimens, indicating that the viable form of the strain reached the intestines $(17,63)$. Defecation frequency in subjects with mild constipation (less than 7 defecations per week) increased $(17,63)$. Pregnant women are prone to suffer from constipation and would prefer not to take medicines to avoid any negative effect on the fetus. Administration of LC1 yogurt to pregnant women successfully increased blood phagocytic activities and improved mild constipation and vaginal flora (43). These human studies suggest that the administration of $L$. johnsonii La1 may contribute to the strengthening of the natural defense systems of healthy humans through natural immunity reinforcement and improvement of intestinal microflora.

In breast-fed infants, the intestinal surface is protected by $\operatorname{Ig} \mathrm{A}$ derived from breast milk during lactation. $\operatorname{Ig} \mathrm{A}$ in the intestinal tract hits its lowest point during the weaning period, when infants stop lactation and have to depend on their own IgA production. In a mouse model, we observed that La1 strain feeding contributed to the maintenance of a higher total IgA level during the weaning period (Fig. 2A) (27). A feeding trial using infant formula with Bifidobacterium Bb-12 in children during and after weaning was also performed and we found an increase in fecal bifidobacteria and $\operatorname{Ig} \mathrm{A}$ production $(15,16)$. Schiffrin et al. demonstrated that feeding of the Bb-12 strain increased blood phagocytic activity in healthy adults as does feeding of the La1 strain (52). Saavedra et al. showed that a probiotic formula reduced the risk of infectious diaherrea in children (48), suggesting that the improvement of intestinal microflora and reinforcement of natural and acquired immunity may have contributed to the anti-infectious effect of the probiotic formula.

We also found fecal total IgA increased through intake of the La1 strain in a 21-month-old aged mouse, an elderly model whose immunity was dysfunctioned (Fig. 2B) (26). In another aged mouse model, we also found recovery of serum IgM level by the La1 strain feeding. In in vitro and ex vivo models, respectively, the La1 strain induced production of CAP-18 and $\alpha$-defensin $(29,30)$, which are bactericidal peptides produced by the host in the intestinal tract and play roles in natural defense of the host (37). These findings suggest that probiotics may reinforce local and systemic immunity non-specifically, resulting in protection of the host from infection, especially in subjects with an age-related compromise of immune functions.

\section{PROBIOTICS AND INFECTIONS IN THE ELDERLY}

The proportion of elderly amongst many Western populations is increasing. Morbidity and mortality from infectious diseases are high in the elderly (32), among whom the natural defense systems including immune functions are compromised, a factor which is the primary cause of an increase in the risk of diseases $(38,39)$. Changes in the intestinal microflora balance among the elderly have been reported $(25,40)$, which may attenuate the host defense. Probiotics have the potential to 

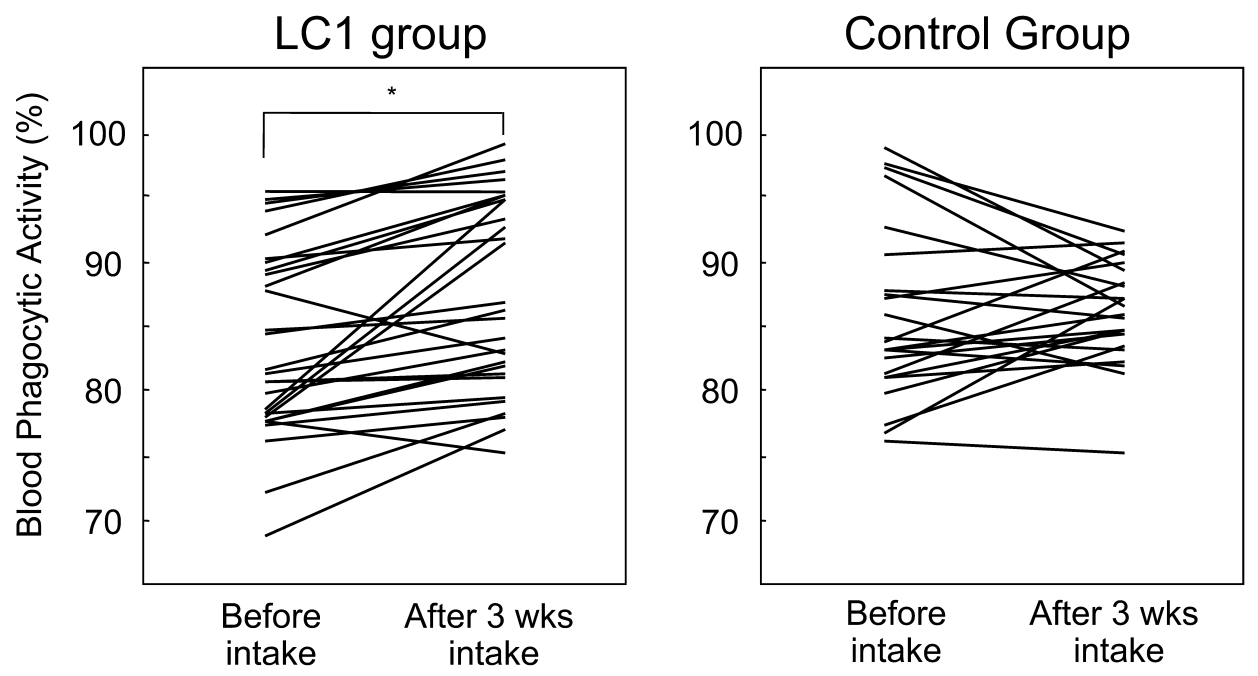

Fig. 1. Feeding of fermented milk with L. johnsonii La1 $\left(\mathrm{LC}_{\mathbb{R}}\right)$ for 3 weeks increased blood phagocytic activity, a biomarker for natural immunity, in healthy adults (aged 20-59 years of age, $\mathrm{n}=30) .{ }^{*} \mathrm{p}<0.001$ compared between before and after administration.

improve host immunity, however, there is less evidence of their efficacy against infections and in improvement of nutritional status in the elderly, who are at high risk of infections due to depression of the immune and digestive systems.

We conducted two double-blind placebo controlled feeding trials in the elderly to elucidate the effects of LC1 fermented milk on the incidence of infections and their immune status. In the first study with a parallel feeding design (42), 24 completely enterally-fed elderly inpatients aged over 70 yrs were enrolled. After a 12week run-in observation period, a part of the enteral nutrition was replaced by fermented milk with the La1 strain in the LC1-fed group for 12 weeks. The percentage of days with infections, comprehensively diagnosed by a physician as in need of a prescription of antibiotics, significantly decreased to one third within the 12 weeks months feeding period in the LC1-fed subjects (Fig. 3A). There were no changes in subjects of the control diet-fed group. Blood phagocytic activity significantly increased in the LC1-fed elderly subjects whose initial level was low, indicating that reinforcement of natural immunity by the probiotic feeding may be attributed, at least partially, to risk reduction of infections.

Interestingly, the total count of fecal bacteria in the elderly subjects of this study was very low at approximately $10 \log 10$ number per wet feces, and there were no changes in fecal microflora observed during the probiotic feeding, suggesting that the natural immunity reinforcement found in that study was exerted not by proportional changes in intestinal microflora indirectly derived from probiotic feeding, but by stimulation of the La1 strain directly. Some researchers have shown that nutritional supplements can work to enhance immunity and suppress infectious diseases $(6,14,58)$, but they do not always work sufficiently $(20,21)$. The enteral nutrition formula we used for the elderly in both groups was already rich in zinc, vitamins and poly-unsaturated fatty acids which are reported to reinforce host immunity and/or to reduce the risk of infections $(4,14,58)$, suggesting that the probiotic strain may work on top of such nutritional supplements for the elderly.

In a second study with a double blind-placebo controlled cross-over design on healthy elderly living at a nursing home with usual meal services (66), we observed an increase in blood phagocytic activity in the elderly with initially low levels of the activity by 5 -week probiotic feeding. In some volunteers, influenza vaccination was conducted and we observed a greater increase in serum influenza antibody titer after LC1 fermented milk feeding compared to placebo feeding. Link-Amster et al. demonstrated that ingestion of probiotic fermented milk with the La1 strain significantly increased serum specific IgA antibody titer in healthy adult subjects orally vaccinated with Salmonella typhi Ty21a (34). Probiotic feeding may support the efficacy of vaccination in healthy subjects. 

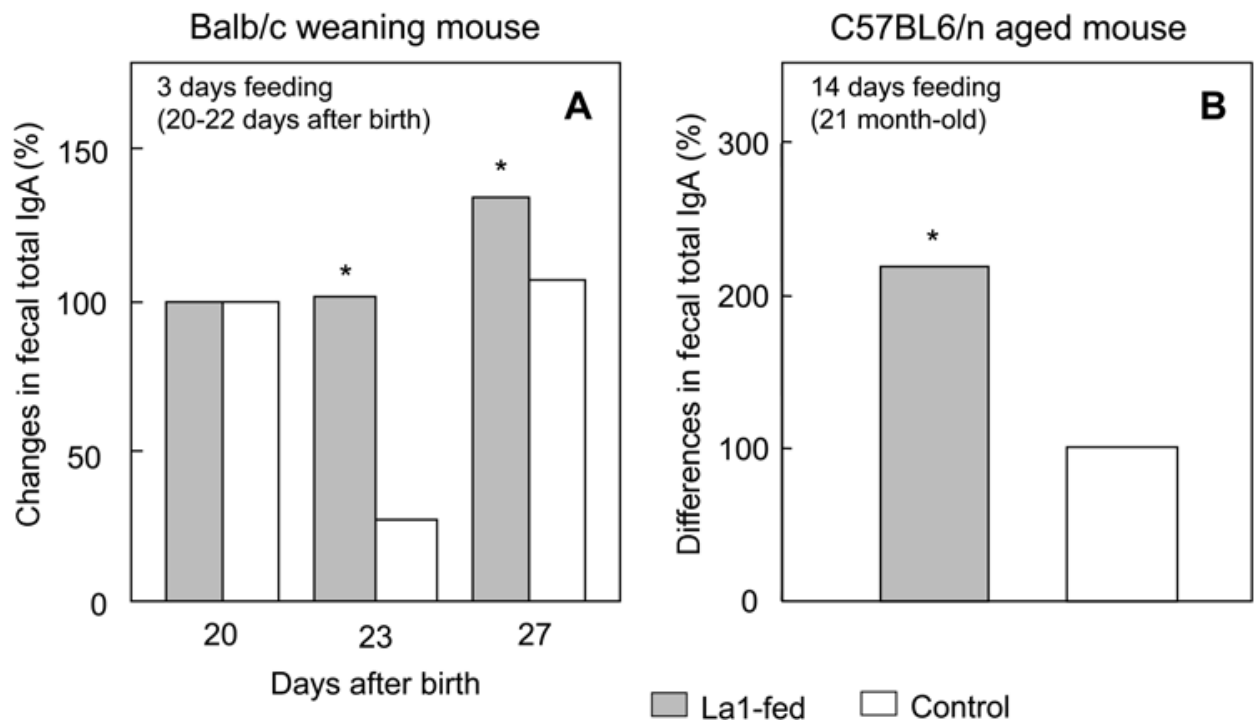

Fig. 2. Fecal total IgA increased in weaning (A) and aged (B) mice administered L. johnsonii La1. Gray and white bars showed the Lal-fed and control groups, respectively. ${ }^{*} \mathrm{p}<0.05$ compared between two feeding groups.
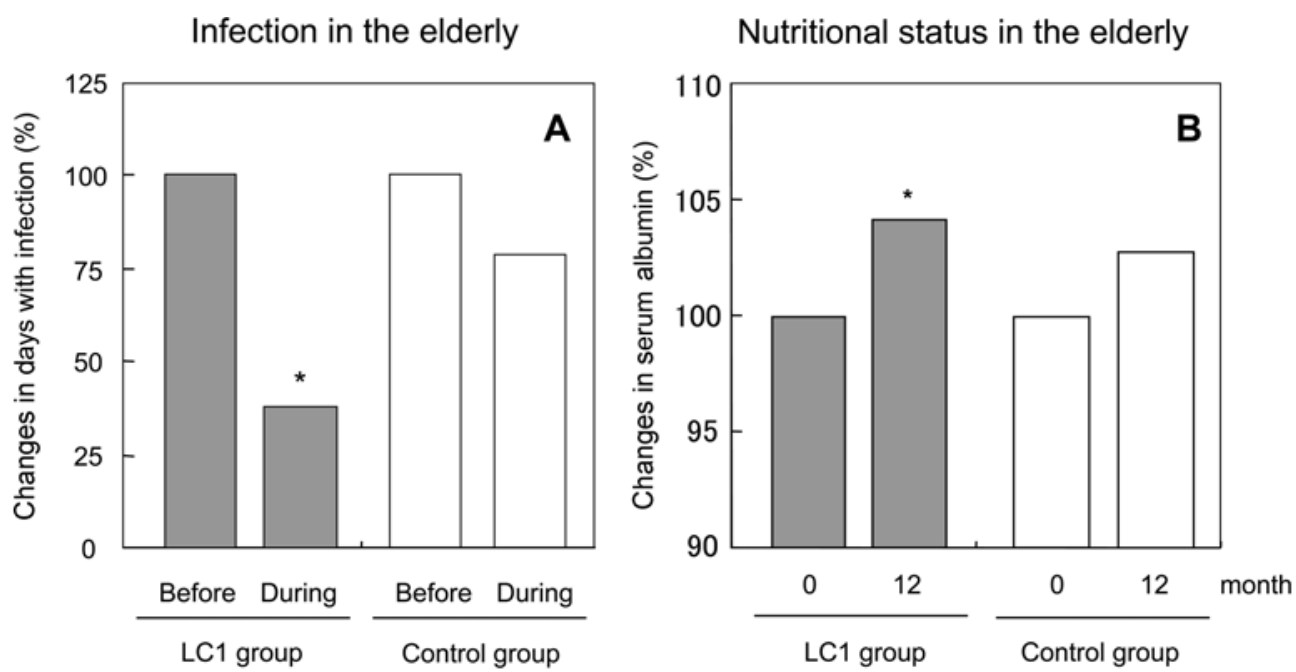

Fig. 3. Fermented milk with L. johnsonii La1 $\left(\mathrm{LC}_{\mathbb{R}}\right)$ fed for 3 months suppressed the frequency of infections (A) and increased serum albumin, a nutritional status biomarker $(B)$, in tube-fed elderly $(n=24)$. $*_{p}<0.05$ compared with before administration.

\section{NUTRITIONAL STATUS AND INFLAMMATION}

Nutritional status is easily compromised in the elderly, especially in hospitalized and enterally-fed elderly (55); it also causes dysfunction of the immune system $(31,33,35)$. In both trials of feeding the La1 strain to the elderly mentioned above, we also found an increase in serum albumin, a nutritional status biomarker (Fig. 3B) (42, 66). Improvement of nutritional status could play a key role in regulating infections by revitalizing the immune system and organs. In infants, it has been shown that probiotics can be a potential means for recovery from malnutrition by reducing diarrhea through normalizing intestinal microflora (54). In our studies on the elderly, there were few cases of diarrhea and there was no difference in its incidence between the test and control groups, suggesting that the improvement of nutritional status 
found in the elderly subjects fed probiotics was not associated with diarrhea.

Probiotic feeding has the potential to increase the absorption of micronutrients through acidification of the intestinal tract (22) or the provision of short chain fatty acids, a growth factor for the intestinal epithelium (50). Intestinal bacteria may also supply micronutrients as bacterial metabolites (7). However, these are not likely to have occurred in the tube-fed elderly subjects of our study, because we did not find any improvement in their fecal condition or microflora. Recently, we found that duodenal administration of the La1 strain stimulated the parasympathetic nervous system in vivo, as results, we observed a decrease in blood pressure (Fig. 4) and blood glucose level in rats $(57,65)$. Physiological declines of gastrointestinal functions, not only on immunological but also neurological and metabolic systems, occur in aged populations (13). The probiotic strain may act as an anabolic stimulus to the intestines and revitalize the digestive and absorption systems.

Inflammation has a strong effect on aging and the health status of the elderly. Longevity may be associated with genotype of pro- and anti-inflammatory cytokines, TNF- $\alpha$ and IL-10 production, respectively (36). Haller et al. indicated that the La1 strain well-induced expression of TGF- $\beta$, an anti-inflammatory cytokine from epithelial cells in an in vitro co-cultured system (23). Vidal et al. showed that TNF- $\alpha$ induced from epithelial cells with non pathogenic Escherichia coli is suppressed by lipotichoic acid isolated from the Lal strain in vitro (60). We observed that serum TNF- $\alpha$ decreased in probiotic-fed elderly subjects (42). Regulation of inflammation may occur directly through the immune system modulation by the La1 strain or

\section{Sympathetic adrenal nerve}
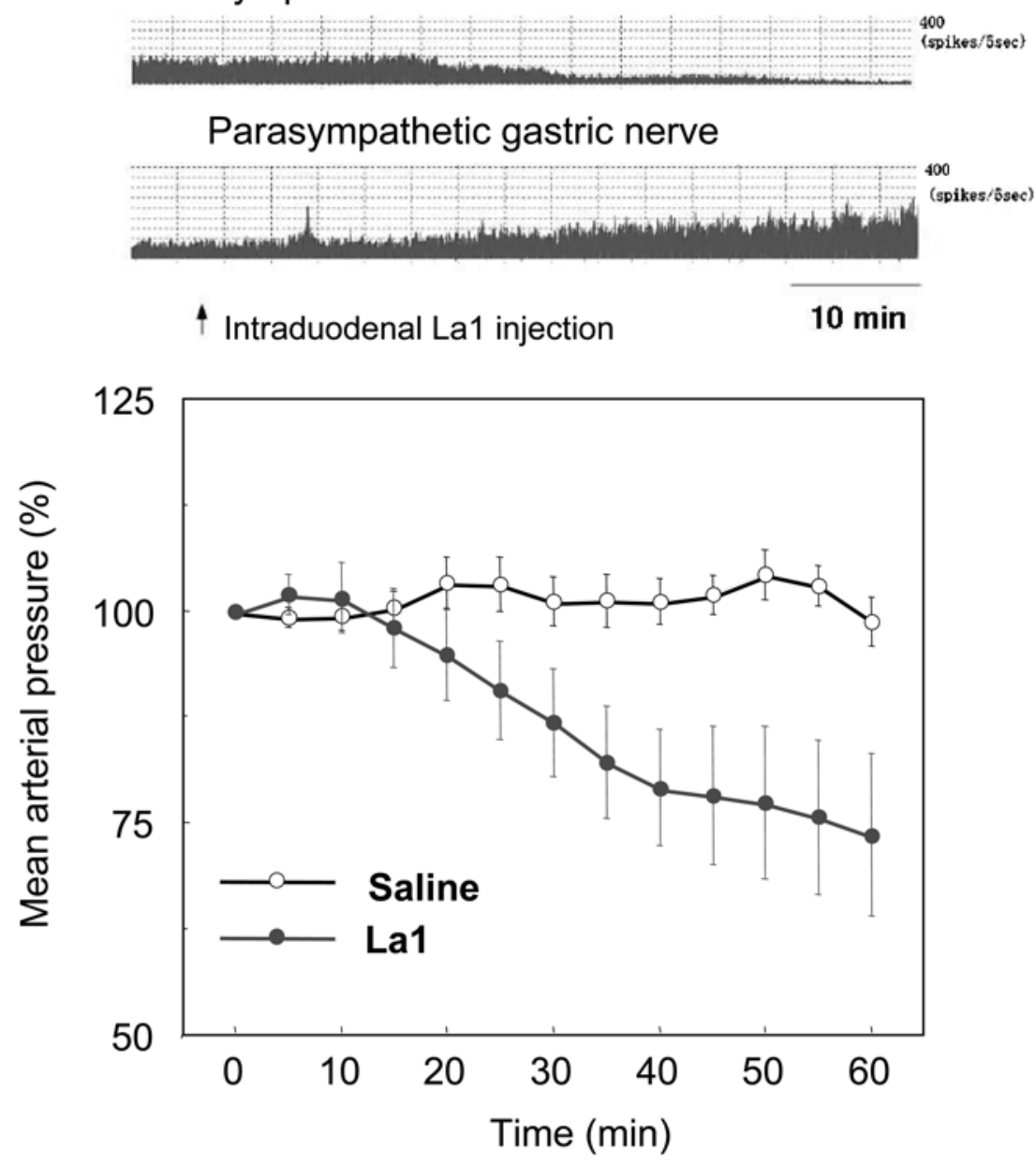

Fig. 4. Duodenal injection of $L$. johnsonii La1 stimulated parasympathetic nerves in rats, resulting in lower blood pressure. 


\section{Skin inflammation in NC/NgaTnd mouse (16 week of age)}

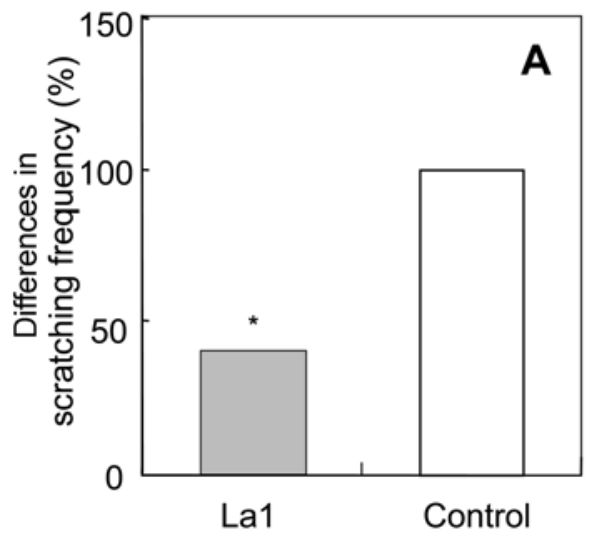

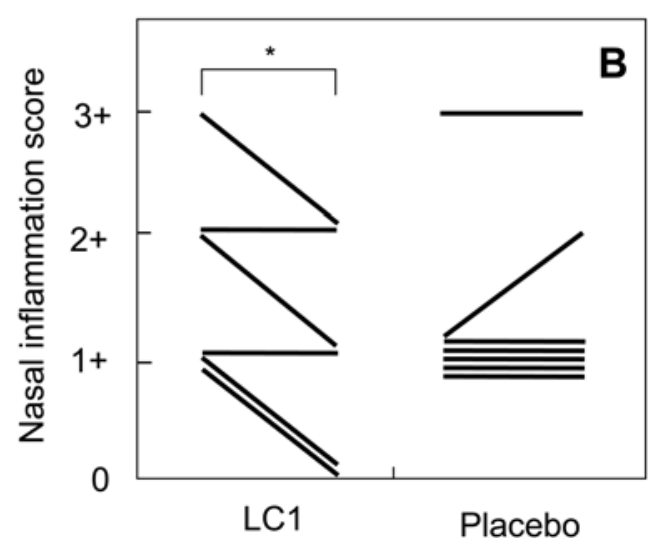

Fig. 5. Feeding of $L$. johnsonii La1 for 4 weeks during the weaning period suppressed skin inflammation in an atopic dermatitis mouse model (A). Feeding of fermented milk with the La1strain $\left(\mathrm{LC} 1_{\mathbb{B}}\right)$ improved the nasal mucosa inflammation score in cedar pollen allergy patients who participated in a double-blind placebo controlled study (B). ${ }^{*} \mathrm{p}<0.05$ compared between before and after administration.

indirectly through suppression of infections as a result. The anti-inflammatory effect of probiotics could contribute the maintenance of health in the elderly through the improvement of immune and nutritional status, sometimes by limiting unexpected energy expenditure and damage to the body caused by fever.

In terms of the anti-inflammatory action of probiotics, allergy is an important target. In NC/Nga Tnd mice, which spontaneously develop atopic dermatitis-like skin symptoms in a conventional condition, 4-week feeding of the La1 strain during the weaning period significantly suppressed skin symptoms at 16 weeks of age (Fig. 5A), and expression of pro-inflammatory cytokines was regulated in their skin (64). In a pilot human trial using subjects with cedar pollen allergy, we found that 3-week feeding of LC1 fermented milk decreased nasal mucosa inflammation (Fig. 5B) (18). We also conducted an animal trial using a DSS colitis model, and showed that inflammation score of the intestines was improved especially when the La1 strain was fed before DSS ingestion (45). In a $H$. pyroli infected animal model, gastric inflammation was suppressed by administration of the La1 strain (62). Probiotics such as the La1 strain could potentially be a tool for regulating diseases with inflammatory responses.

A schematic figure showing how the probiotic La1 strain might work as an anti-infectious agent is provided in Fig. 6. An important primary target of probiotics could be intestinal microflora, which exert colonization resistance to exclude pathogens, stimulate the immune systems and improve absorption of nutrients. Immune systems are also an important target for probiotics, which directly exert an anti-infectious effect on the human body. We unexpectedly found that probiotics could stimulate immunity even when intestinal microflora was not changed in tube feeding elderly. Our unique finding in the probiotics feeding trial in the elderly was nutritional status improvement, which may have had a positive effect on the immune systems. Stimulation of the parasympathetic nerve system by probiotics, may contribute to nutritional status improvement. The reduction of infections themselves may also contribute to nutritional status improvement through regulation of inflammation and unexpected energy expenditure caused by fever due to infections. Further studies are necessary, but probiotic strains such as L. johnsonii La1 may contribute to the improvement of natural host defense, resulting in eliciting an anti-infectious effect.

\section{CONCLUSION}

We have been investigating probiotic strains Lactobacillus johnsonii La1 (NCC533) and Bifidobacteirum lactis Bb-12 aiming at elucidating the efficacy of these probiotic strains in strengthening the natural defense systems of the host and their potential to reduce the risk of infections as an end-point benefit. Lal 


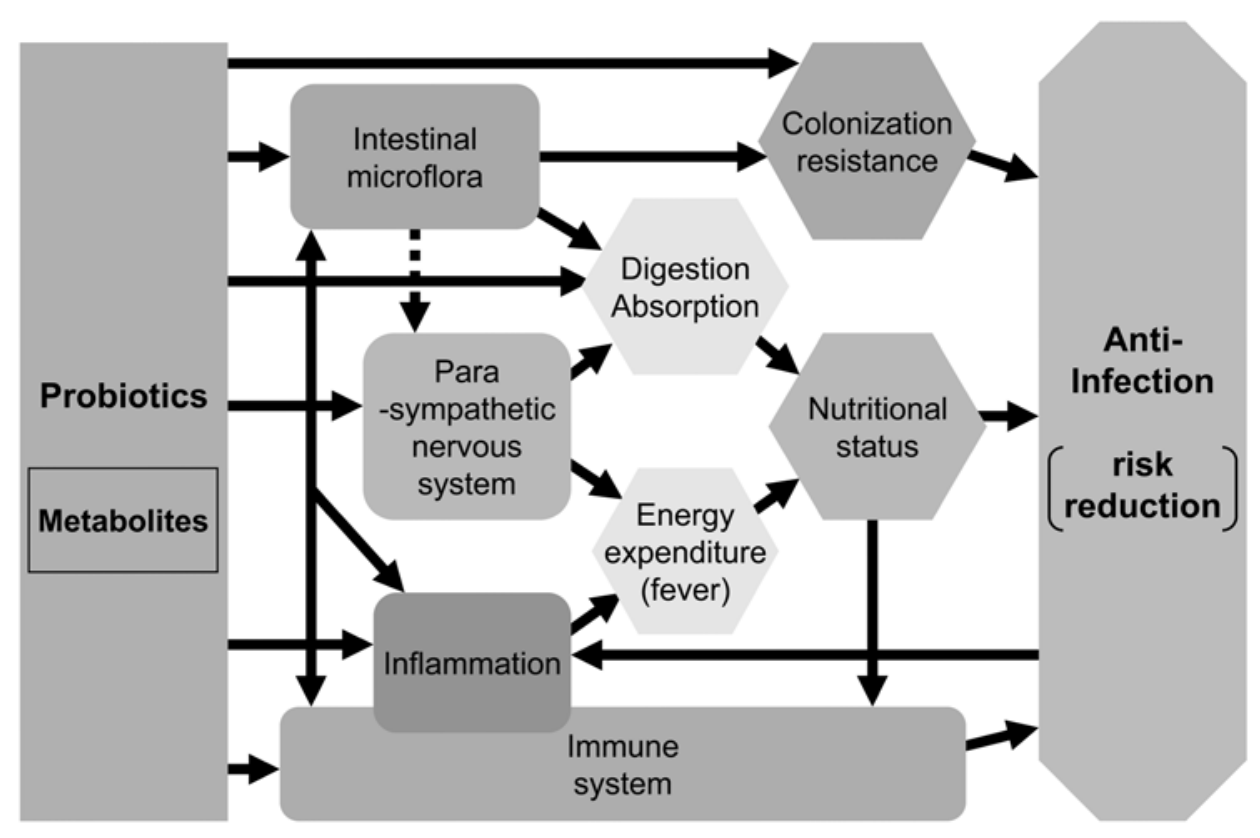

Fig. 6. Schematic flow of how probiotics strengthen the natural defense system and exert an antiinfectious effect.

strain feeding in adults reinforced blood phagocytic activity, a useful biomarker of natural immunity, and improved intestinal microflora. Feeding of the Bb-12 strain in weaning children also improved intestinal microflora and increased local IgA production. A feeding trial in the elderly inpatients showed that frequency of infection was reduced by the feeding of the La1 strain, and natural immunity and nutritional status improved. The La1 strain was shown to stimulate the parasympathetic nerve system, implying that anabolic action might contribute to nutritional status improvement. An anti-inflammatory effect of the La1 strain was also suggested by animal studies using colitis, Helicobacter pylori-infection, and atopic dermatitis models, and human studies in elderly and pollen allergy patients. Immune systems are originally developed by the host to fight exogenous microbes. Probiotics are basically bacteria, not harmful to the host but possiblly stimulate the immune systems. Probiotics, acting as stimuli not only on the immune system but also the auto nervous system, could possibly be of great benefit to the host. Probiotics such as L. johnsonii La1 and B. lactis $\mathrm{Bb}-12$ could play a significant role in improving the QOL of human beings by strengthening the natural defenses of the host.

Acknowledgements. We would like to express our sincere appreciation to Prof. S. Kaminogawa (Nihon University) and Emeritus Prof. T. Mitsuoka (The University of Tokyo), for leading the activity of the Applied Science Board for Lactic Acid Bacteria and supporting all research works. We also greatly appreciate Prof. H. Iino (Showa Women's University), Prof. Y. Yamashiro (Juntendo University School of Medicine), and Prof. H. Ohigashi (Kyoto University) for supervising research work coordination. We would like to thank Emeritus Prof. Nagai (Osaka University), Prof. H. Matsuda (Tokyo University of Agriculture and Technology), Prof. K. Ushida (Kyoto Prefectural University), Dr. Y. Takagi (Osaka Prefectural Institute of Public Health), Dr. S. Miyaguchi (Harunaso Hospital), Dr. T. Ohkusa (Juntendo University School of Medicine), Prof. T. Yamamoto (Niigata University), Emeritus Prof. Y. Yamori (Kyoto University), Prof. T. Ayabe (Hokkaido University), Prof. H. Isogai (Sapporo Medical University), Prof. K. Itoh (The University of Tokyo ), Dr. K. Nishijima (Fukui University), Dr. T. Kaburagi and Prof. K. Satoh (Nihon Women's University), and their colleagues who collaboratively conducted research works. I would like to give special thanks to Dr. S. Blum, Dr. E. Schiffrin, Dr. T. van der Weid, Dr. F. Rochat and their colleagues at Nestlé Research Center, Mr. T. Yamano and all staff at Nestlé Japan Ltd., and the other collaborators who supported our research work. 


\section{REFERENCES}

(1) Bernet MF, Brassart D, Neeser JR, Servin AL. 1994. Lactobacillus acidophilus La1 binds to cultured human intestinal cell lines and inhibits cell attachment and cell invasion by enterovirulent bacteria. Gut 35: 483-489.

(2) Bernet-Camard MF, Lievin V, Brassart D, Neeser JR, Servin AL, Hudault S. 1997. The human Lactobacillus acidophilus strain Lal secretes a nonbacteriocin antibacterial substance(s) active in vitro and in vivo. Appl Environ Microbiol 63: 2747-2753.

(3) Blum S, Reniero R, Schiffrin EJ, Crittenden R, Mattila Sandholm T, Ouwehand AC, Salminen S, Wright A, von Saarela M, Saxelin M, Collins K, Morelli L. 1999. Adhesion studies for probiotics: need for validation and refinement. Trends Food Sci Technol 10: 405.

(4) Bowdish DM, Davidson DJ, Hancock RE. 2006. Immunomodulatory properties of defensins and cathelicidins. Curr Top Microbiol Immunol 306: 2766.

(5) Butcher S, Chahel H, Lord JM. 2000. Review article: ageing and the neutrophil: no appetite for killing? Immunology 100: 411-416.

(6) Chandra RK. 1992. Effect of vitamin and traceelement supplementation on immune responses infections in elderly subjects. Lancet 340: 1124-1127.

(7) Deguchi Y, Morishita T, Mutai M. 1985. Comparative studies on synthesis of water-soluble vitamins among human species of bifidobacteria. Agric Biol Chem 49: 13-19.

(8) de Vrese M, Winkler P, Rautenberg P, Harder T, Noah C, Laue C, Ott S, Hampe J, Schreiber S, Heller K, Schrezenmeir J. 2005. Effect of Lactobacillus gasseri PA 16/8, Bifidobacterium longum SP 07/3, B. bifidum MF $20 / 5$ on common cold episodes: a double blind, randomized, controlled trial. Clin Nutr 24: 481-491.

(9) Dineen P. 1961. The effect of alterations in intestinal flora on host resistance to systemic bacterial infection. J Infect Dis 109: 280-286.

(10) Esparza B, Sanchez M, Barranquero M, Sabiono E, Merino F. 1996. Neutrophil function in elderly persons assessed by flow cytometry. Immunol Invest 25: 185-190.

(11) FAO/WHO Joint Working Group. Guidelines for the evaluation of probiotics in food. May 2002 WHO.

(12) Felley CP, Corthesy-Theulaz I, Rivero JB, Sipponen P, Kaufmann M, Bauerfeind P, Wiesel PH, Brassart D, Pfeifer A, Blum AL, Michetti P. 2001. Favourable effect of an acidified milk (LC-1) on Helicobacter pylori gastritis in man. Eur J Gastroenterol Hepatol 13: 25-29.

(13) Firth M, Prather CM. 2002. Gastrointestinal motility problems in the elderly patient. Gastroenterol 122: 1688-1700.

(14) Fortes C, Forastiere F, Agabiti N, Fano V, Pacifici R, Virgili F, Piras G, Guidi L, Bartoloni C, Tricerri A, Zuccaro P, Ebrahim S, Perucci CA.1998. The effect of zinc and vitamin A supplementation on immune response in an older population. J Am Geriatr Soc 46: 19-26.

(15) Fukushima Y, Kawata Y, Hara H, Terada A, Mitsuoka T. 1998. Probiotic formula enhances intestinal immunoglobulin A production in healthy children. Int J Food Microbiol 42: 39-44.

(16) Fukushima Y, Li, Shou-Tou, Hara H, Terada A, and Mitsuoka T. 1997. Effect of follow-up formula containing bifidobacteria (NAN BF) on fecal flora and fecal metabolites in healthy children. Biosci Microflora 16: 65-72.

(17) Fukushima Y, Yamano T, Kusano A, Takada M, Amano M, Iino H. 2004. Effect of fermented milk containing Lactobacillus johnsonii La1 (LC1) on defecation in healthy Japanese adults - a double blind placebo controlled study -. Biosci Microflora 23: 139147.

(18) Fukushima Y, Yamano T, Kusano A, Takada M, Amano M, Muraki H, Iino H. 2005. Effect of fermented milk containing Lactobacillus johnsonii La1 (LC1) on constipation and pollen allergy in adults (a double blind placebo controlled study). J Jap Soc Nutr Food Sci 58: S46.

(19) Fuller R.1991. Probiotics in human medicine. Gut 32: 439-442.

(20) Girodon F, Galan P, Monget AL, Boutron-Ruault MC, Brunet-Lecomte P, Preziosi P, Arnaud J, Manuguerra JC, Herchberg S. 1999. Impact of trace elements and vitamin supplementation on immunity and infections in institutionalized elderly patients: a randomized controlled trial. MIN. VIT. AOX. geriatric network. Arch Intern Med 159: 748-754.

(21) Graat JM, Schouten EG, Kok FJ. 2002. Effect of daily vitamin $\mathrm{E}$ and multivitamin-mineral supplementation on acute respiratory tract infections in elderly persons: a randomized controlled trial. JAMA 288: 715-721.

(22) Greger JL. 1999. Nondigestible carbohydrates and mineral bioavailability. J Nutr 129 (7 suppl): 1434S$1435 \mathrm{~S}$.

(23) Haller D, Bode C, Hammes WP, Pfeifer AM, Schiffrin EJ, Blum S. 2000. Non-pathogenic bacteria elicit a differential cytokine response by intestinal epithelial cell/leukocyte co-cultures. Gut 47: 79-87.

(24) Hatakka K, Savilahti E, Ponka A, Meurman JH, Poussa T, Nase L, Saxelin M, Korpela R. 2001. Effect of long term consumption of probiotic milk on infections in children attending day care centres: double blind, randomized trial. Br Med J 322: 1327 1331.

(25) Hopkins MJ, Sharp R, Macfarlane GT. 2001. Age and disease related changes in intestinal bacterial populations assessed by cell culture, 16S rRNA abundance, and community cellular fatty acid profiles. Gut 28: 198-205.

(26) Hosoda T, Yamano T, Fukushima Y, Sato K. 2003. Influence of Lactobacillus johnsonii La1 on the intestinal immune function in protein energy malnutrition. Geriatr Gerontol Int 3: S118. 
(27) Inoue R, Nishio A, Fukushima Y, Ushida K. 2006. Administration of probiotic Lacobacillus johnsonii NCC533 (La1) in a specific time of the weaning period prevents the development of atopic dermatitis induced after maturation in model mice, $\mathrm{NC} / \mathrm{Nga} . \mathrm{Br} \mathrm{J}$ Dermatol (in press).

(28) Isolauri E, Arvola T, Sutas E, Moilanen E, Salminen S.2000. Probiotics in the management of atopic eczema. Clinical Experiment Allergy 30: 1604-1610.

(29) Itoh T, Ayabe T, Kogo Y. 2005. Jpn J Gastoenterol 102: A140

(30) Isogai H, Isogai E, Okumura K, Hirose K. 2006. Strategy for survival in lactic acid bacteria through bacterial components and inducing substances. Jpn J Lactic Acid Bacteria 17: 40-46.

(31) Keusch GT. 2003. The history of nutrition: malnutrition, infection and immunity. J Nutr 133: 336S-340S.

(32) Klima MP, Povysil C, Teasdale TA. 1997. Causes of death in geriatric patients: a cross-cultural study. $\mathrm{J}$ Gerontol A Biol Sci Med Sci 52: M247-253.

(33) Lesourd B. 2004. Nutrition:a major factor influencing immunity in the elderly. J Nutr Health Aging 8: 28-37.

(34) Link-Amster H, Rochat F, Saudan KY, Mignot O. Aeschlimann JM. 1994. Modulation of a specific humoral immune response and changes in intestinal flora mediated through fermented milk intake. FEMS Immunol Med Microbiol 10: 55-64.

(35) Linton PJ, Dorshkind K. 2004. Age-related changes in lymphocyte development and function. Nat Immunol 5: 133-139.

(36) Lio D, Scola L, Crivello A, Colonna-Romano G, Candore G, Bonafe M, Cavallone L, Marchegiani F, Olivieri F, Franceschi C, Caruso C. 2003. Inflammation, genetics, and longevity: further studies on the protective effects in men of IL-10 -1082 promoter SNP and its interaction with TNF-alpha-308 promoter SNP. J Med Genet 40: 296-299.

(37) Macpherson AJ, Hunziker L, McCoy K, Lamarre A. 2001. IgA responses in the intestinal mucosa against pathogenic and non-pathogenic microorganisms. Microbes Infect 3: 1021-1035.

(38) Makinodan T. 1995. Patterns of age-related immunologic changes. Nutr Rev 53: S27-31.

(39) Miller RA. 1996. The aging immune system: primer and prospectus. Science 273: 70.

(40) Mitsuoka T, Hayakawa K. 1972. Die Faekalflora bei Menchen. I \& Mitteilung. Die Zusammensetsung der faekalflora der verschiedenen altersgruppen. Zentralbl Bakteriol Hyg I Abt Orig A223: 333-342.

(41) Mitsuoka T, Ohno K, Bennno Y, Suzuki K, Nanba K. 1976. The fecal flora of man. IV. Communication of the newly developed method with the old conventional method for the analysis of intestinal flora. Zentralbl Bakteriol Hyg I Abt Orig A234: 219-233.

(42) Miyaguchi S, Kaburaki T, Yamano T, Fukushima Y, Sato K. 2004. Effect of Lactobacillus johnsonii La1 on the nutritional conditin, immunity and MRSA carrier in elderly inpatients. J Nutr Health Aging 8: 450.

(43) Nishijima K, Shukunami K, Kotsuji F, Yamano T, Fukushima Y, Iino H. 2006. Eur J Obsterics Gynecol Reproduct Biol 125: 146-147.

(44) Deguchi Y, Morishita T, Mutai M. 1985. Comparative studies on synthesis of water-soluble vitamins among human species of bifidobacteria. Agric Biol Chem 49: 13-19.

(45) Ohkusa T, Nomura T, Sato N. 2005. Prophlactic effect of Lactobacillus johnsonii La1 on DSS-induced colitis in mice. Jpn J Gastoenterol 102: A138.

(46) Pantoflickova D, Corthesy-Theulaz I, Dorba G, Stolte M, Isler P, Rochat F, Enslen M, Blum AL. 2003. Favorable effect of regular intake of fermented milk containing Lactobacillus johnsonii on Helicobacter pylori associated gastritis. Aliment Pharm Ther 18: 805-813.

(47) Pridmore RD, Berger B, Desiere F, Vilanova D, Barretto C, Pittet AC, Zwahlen MC, Rouvet M, Altermann E, Barrangou R, Mollet B, Mercenier A, Klaenhammer T, Arigoni F, Schell MA. 2004. The genome sequence of the probiotic intestinal bacterium Lactobacillus johnsonii NCC 533. Proc Natl Acad Sci U S A 101: 2512-2517.

(48) Saavedra JM, Bauman NA, Oung I, Perman JA, Yolken RH.1994. Fedding of Bificobacterium bificum and Streptococcus thermophilus to infants in hospital for prevention of diarrhoea and shedding of rotavirus. Lancet 344: 1046-1049.

(49) Saavedra JM, Tschernia A. 2002. Human studies with probiotics and prebiotics: clinical implications. Br J Nutr 87 (Suppl 2): S241-246.

(50) Sakata T. 1995. Effect of short-chain fatty acids on the proliferation of gut epithelial cells in vivo. In Physiological and Clinical Aspects of Short-chain Fatty Acids, Cummings JH, Rombeau JL, Sakata T (eds), Chambridge University Press, p. 289-305.

(51) Schelonka RL, Infante AJ. 1998. Neonatal immunology. Semin Perinatol 22: 2-14.

(52) Schiffrin EJ, Rochat F, Link-Amster H, Aeschlimann JM, Donnet-Hughes A. 1995. Immunomodulation of human blood cells following the ingestion of lactic acid bacteria. J Dairy Sci 78: 491-497.

(53) Schneider SM, Le Gall P, Girard-Pipau F, Piche T, Pompei A, Nano JL, Hebuterne X, Rampal P. 2000. Total artificial nutrition is associated with major changes in the fecal flora. Eur J Nutr 39: 248-255.

(54) Solis B, Samartin S, Gomez S, Nova E, de la Rosa B, Marcos A. 2002. Probiotics as a help in children suffering from malnutrition and diarrhea. Eur J Clin Nutr 56 (Suppl 3): S57-59.

(55) Sullivan DH. 2000. Undernutrition in older adults. Ann Long-Term Care 8: 41-46.

(56) Szajewska H, Mrukowicz JZ. 2001. Probiotics in the treatment and prevention of acute infectious diarrhea in infants and children: a systematic review of published randomized, double-blind, placebocontrolled trials. J Pediatr Gastroenterol Nutr Suppl 2: 
S17-25.

(57) Tanida M, Yamano T, Maeda K, Okumura N, Fukushima Y, Nagai K. 2005. Effects of intraduodenal injection of Lactobacillus johnsonii La1 on renal sympathetic nerve activity and blood pressure in urethane-anesthetized rats. Neurosci Lett 389: 109114.

(58) Thies F, Miles EA, Nebe-von-Caron G, Powell JR, Hurst TL, Newsholme EA, Calder PC. 2001. Influence of dietary supplementation with long-chain n-3 or n-6 polyunsaturated fatty acids, decreases natural killer cell activity in healthy subjects aged $>55 \mathrm{y}$. Am J Clin Nutr 73: 539-548.

(59) Turchet P, Laurenzano M, Auboiron, Antoine JM. 2003. Effect of fermented milk containing the probiotic Lactobacillus casei DN-114001 on winter infections in free-living elderly subjects: a randomized, controlled pilot study. J Nutr Health Aging 7: 75-77.

(60) Vidal K, Donnet-Hughes A, Granato D. 2002. Lipoteichoic acids from Lactobacillus johnsonii strain La 1 and Lactobacillus acidophilus strain La10 antagonize the responsiveness of human intestinal epithelial HT29 cells to lipopolysaccharide and gramnegative bacteria Infect Immunity 70: 2057-2064.

(61) Wells CL, Maddaus LA, Jechorek RP, Simmons RL. 1988. Role of intestinal anaerobic bacteria in colonization resistnace. Eur J Clin Microbiol Infect Dis 7: 107-113.

(62) Yamamoto T, Taneike I, Fukushima Y. Inhibitory action of Lactobacillus johnsonii La1 (LC1) against Helicobacter pylori infection and subsequent gastric mucosal lesions. International Workshop of Campylobacter, Helicobacter and Related Organisms 2005.

(63) Yamano $\mathrm{T}$, Iino $\mathrm{H}$, Takada $\mathrm{M}$, Blum S, Rochat $\mathrm{F}$, Fukushima Y. 2006. Improvement of human intestinal flora by ingestion of a probiotic strain of Lactobacillus johnsonii La1. Br J Nutr 95: 303-312.

(64) Yamano T, Tanaka A, Fukushima Y, Matsuda H. 2004. Prophylactic effect of oral administration of Lactobacillus johsonii La1 during weaning period on atopic dermtitis in NC/Nga Tnd mice. Jpn J Allergol 53: 900 .

(65) Yamano T, Tanida M, Niijima A, Maeda K, Okumura N, Fukushima Y, Nagai K. 2006. Effects of the probiotic strain Lactobacillus johnsonii strain La1 on autonomic nerves and blood glucose in rats. Life Sci 79: 1963-1967.

(66) Yamori Y, Sagara M, Chen JJ, Yamano T, Fukushima Y. 2004. Immunopotentiation of influenza vaccination and nutritional improvement by LC1 fermented milk in the elderly. J Nutr Health Aging 8: 448. 